\title{
The Antero-Lateral Thigh Flap in Coverage of Extensive Post Traumatic Upper Limb Defects
}

\author{
Rasha Abdelkader ${ }^{*}$, Hossam El Mahdy' ${ }^{2}$, Tamer Nagy Khairalla ${ }^{3}$, Ayman Mansour ${ }^{4}$, \\ Nisar Haider Zaidi ${ }^{5}$ \\ ${ }^{1}$ Plastic Surgery Department, Kasr Alainy Hospital, Cairo University, Cairo, Egypt \\ ${ }^{2}$ Vascular Surgery Department, Kasr Alainy Hospital, Cairo University, Cairo, Egypt \\ ${ }^{3}$ Orthopedic Surgery Department, Alexandria University, Alexandria, Egypt \\ ${ }^{4}$ Orthopedic Surgery Department, Cairo University, Cairo, Egypt \\ ${ }^{5}$ Department of Surgery, King Abdulaziz University Hospital, Jeddah, Saudi Arabia \\ Email: "rasha.abdelkader@gmail.com
}

Received 14 June 2016; accepted 4 July 2016; published 7 July 2016

Copyright (C) 2016 by authors and Scientific Research Publishing Inc.

This work is licensed under the Creative Commons Attribution International License (CC BY).

http://creativecommons.org/licenses/by/4.0/

(c) (i) Open Access

\begin{abstract}
Objective: To assess the role of antero-lateral thigh flaps in coverage in cases with traumatic injury to the upper limb. Methods: A total of fifteen cases of upper limb trauma were studied between May 2014 and February 2016. Antero-lateral thigh flaps were performed to cover post traumatic upper limb soft tissue defects. Brachial interposition grafts were used in all cases. Harvesting was performed using saphenous vein graft. A $10 \%$ larger than defect, flap was used to cover defect. Results: The age range was 15 to 46 years. All 15 cases were male. The indication for soft tissue reconstruction was trauma all patients. Each procedure was performed by a "two team" approach with an experienced surgeon raising the flap and a team preparing the recipient vessels. Flap size ranged from 15 to $25 \mathrm{~cm}$ in length and from 8 to $10 \mathrm{~cm}$ in width. Ischaemic time ranged from 91 to $157 \mathrm{~min}$. We experienced a $100 \%$ flap success rate, with good cosmesis and return to function in all cases. Only two anastomoses required explorations or revision. Minor complications were seen in two patients including a superficial wound infection and a small wound dehiscence. The donor site was closed directly all cases, light dressing with slab support was utilized in all patients Early postoperative management warming the patient, half-hourly flap observations, and ensuring adequate hydration and urinary output. All patients received antithrombotic therapy. Conclusion: The anterolateral thigh flap is one of the most versatile and useful perforator flaps for multidimensional reconstructions for head and neck, limb, trunk, and perineal region. It can be ultrathin flap for resurfacing and filling dead spaces with superior functional and aesthetic outcomes.
\end{abstract}

\footnotetext{
"Corresponding author.
} 


\section{Keywords}

\section{Anterolateral Thigh Flap, Perforator, Trauma, Defects}

\section{Introduction}

The antero-lateral thigh flap was first introduced by Song et al. in 1984 as a septo-cutaneous flap based on musculo-cutaneous and septo-cutaneous perforators of descending branch of lateral circumflex femoral artery [1]. Lateral thigh flap was described by Baek et al. in 1983 as fascio-cutaneous flap based on branches of profundafemoris [2]. Koshima and Kimata et al. first described the use of antero-lateral flap in reconstruction of defects of head and neck [3] [4]. The perforator may have different pathways such as septo-cutaneous, musculocutaneous, septo-musculo-cutaneous, and the axial pattern leading ultimately to the source vessels. Anterolateral thigh flap gained popularity because it is ideal soft tissue flap and with development of technique of intramuscular perforator dissection [5]-[8]. Wei et al. with his body of work popularized it [9] [10]. Wide caliber pedicle, large skin paddle, versatility and acceptable morbity have resulted in its success. It requires two teams' approach, so it saves time which would have been wasted in repositioning of patient if only one team would be operating on patient. Nowadays trauma is increasing in our lives which result in injuries in trunk and limbs. Tissue loss in trauma patients is devastating for patients and their families. Skin paddle design with multiple skin paddle configurations, central or eccentric orientations, can be tailored to fit in any defect [11]. Microsurgery can be utilized to cover any complex defect. Nowadays trauma has become most common cause of mortality and morbidity among young population. Complex defects are caused by traumatic injury to upper extremity and they require urgent coverage with flap. Due to scaricity of flap which can be used in upper limb like LDflap (latissimus dorsi flap), the use of antero-lateral thigh flap is a viable option. In this paper we utilized anterolateral thigh flap in coverage of post traumatic upper limb defects.

\section{Patients and Methods}

A total of fifteen cases of upper limb trauma were studied between May, 2014 and February, 2016. Antero-lateral thigh flaps were performed to cover post traumatic upper limb soft tissue defects. Brachial interposition grafts were used in all cases. Harvesting was performed using saphenous vein graft. A 10\% larger than defect, flap was used to cover defect.

\section{Procedure}

A line was drawn from the anterior superior iliac spine to the lateral border of the patella representing the septum between the rectus femoris [RF] and vastus lateralis. The flap was centered over the septum. The anterior border of the flap was incised down to the deep fascia overlying rectus femoris, the fascia was sutured to the dermal layer of the anterior border of the flap to prevent shearing of perforators. There after the anterior border of the flap was raised. The interval between RF and tensor fascia lata was identified and the vascular pedicle (descending branch of Lateral circumflex femoral artery) was identified and dissected proximally to its origin from the medial circumflex vessels. If a larger and longer pedicle was required it was dissected based on the main trunk of the Medial circumflex femoral artery and severed at its origin from the deep femoral vessels. The pedicle was sharply dissected distally and freed from the loose-areolar attachment to the vastus intermedius. At that point if the skin perforator was evident in the septum, the posterior border of the flap was incised deep to the fascia and the flap was elevated from distal to proximal fashion. In case the skin perforator was not evident, a cuff of vastus lateralis 1 inch in width was included along the length of the flap to ensure inclusion of the skin perforator. The defect was closed primary in all cases with no tension on the suture line. It is important to mention that both vascular and reconstructive teams worked simultaneously. A proximal medial arm incision was made as far from the defect, as the length of the pedicle permits (after vascular team have placed the reversed saphenous interposition graft). The brachial vessels were exposed (artery and vein) and small side branches were ligated. A subcutaneous tunnel was created between the defect and the proximal arm incision and the deep fascia was incised (to avoid compression of the pedicle). The flap was sutured preliminary to the edges of the defect and the pedicle was passed through the tunnel and retrieved from the proximal arm incision. Anastomosis of artery and vein was done in an end to side fashion to the brachial vessels and venae commitantes. 


\section{Results}

The age range was 15 to 46 years. All 15 cases were male. The indication for soft tissue reconstruction was trauma all patients. Each procedure was performed by a "two team" approach with an experienced surgeon raising the flap and a team preparing the recipient vessels. Flap size ranged from 15 to $25 \mathrm{~cm}$ in length and from 8 to $10 \mathrm{~cm}$ in width. Ischaemic time ranged from 91 to $157 \mathrm{~min}$. We experienced a 100\% flap success rate, with good cosmesis and return to function in all cases. Only two anastomoses required explorations or revision. Minor complications were seen in two patients including a superficial wound infection and a small wound dehiscence. The donor site was closed directly all cases, light dressing with slab support was utilized in all patients Early postoperative management was warming the patient, half-hourly flap observations, ensuring adequate hydration and urinary output. All patients received antithrombotic therapy.

Case 1: 16 years old male patient suffering from road traffic accident affecting the left upper limb underwent saphenous interposition graft repair of the median and ulnar nerves and antero-lateral thigh flap coverage first pic 6 months post operative second pic intra-operative with saphenous interposition graft in place (Figure 1, Figure 2).

Case 2: 27 years old male patient post industrial accident with compound fracture of the left upper limb, external fixation was performed, saphenous interposition grafting and antero-lateral thigh flap intra-operative photos and post operative 3 months (Figure 3, Figure 4).

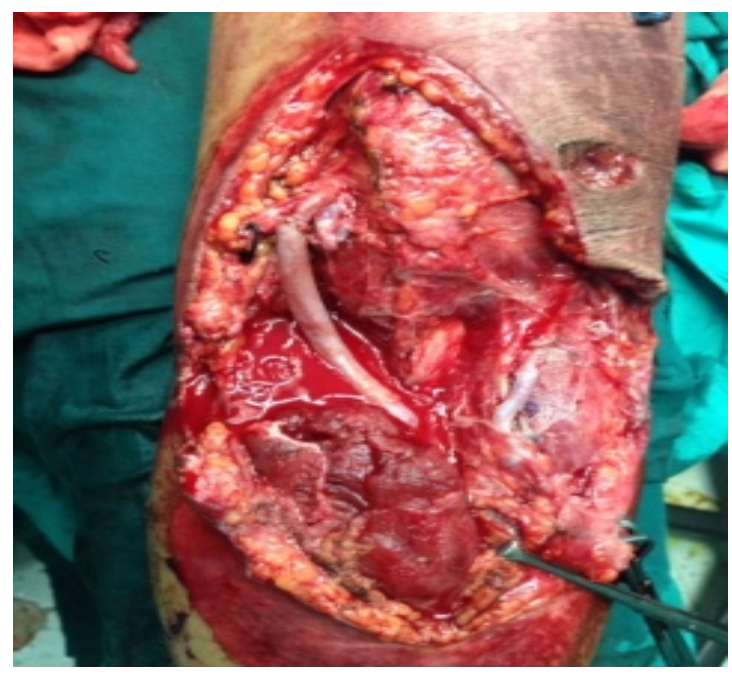

Figure 1. Case-1:intra-operative repair of brachial artery with interposition graft.

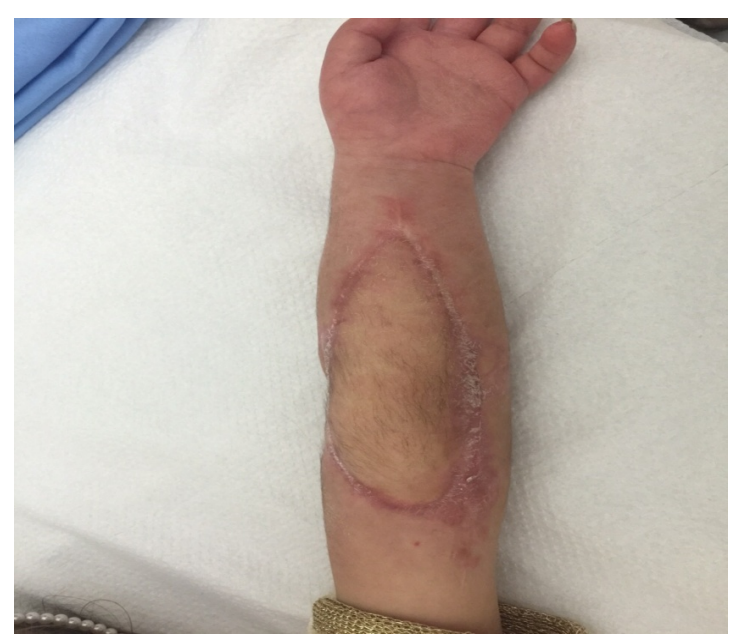

Figure 2. Case-1: Post-op six month RTA. 


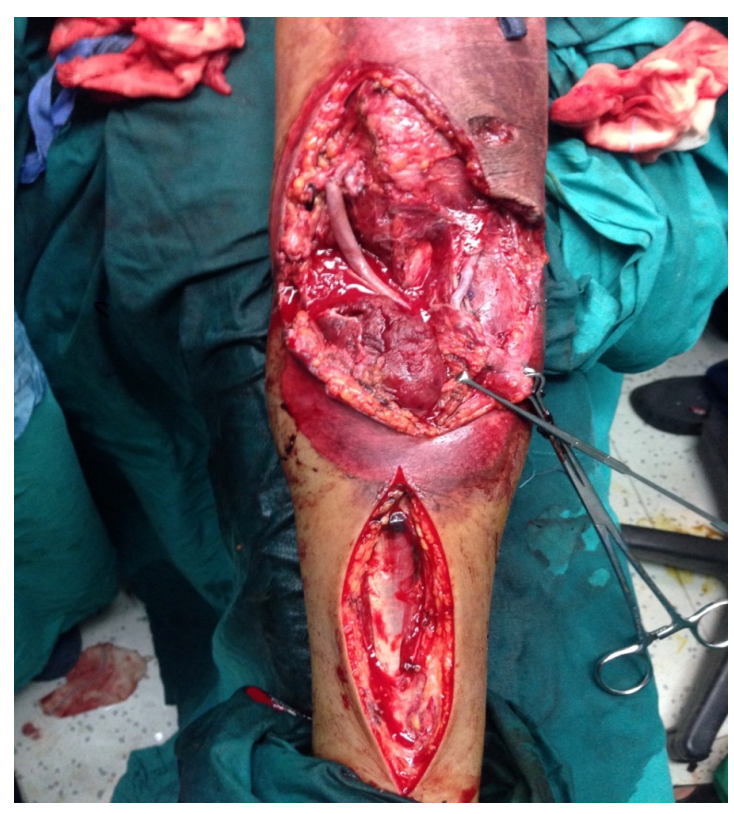

Figure 3. Case-2: intra-operative.

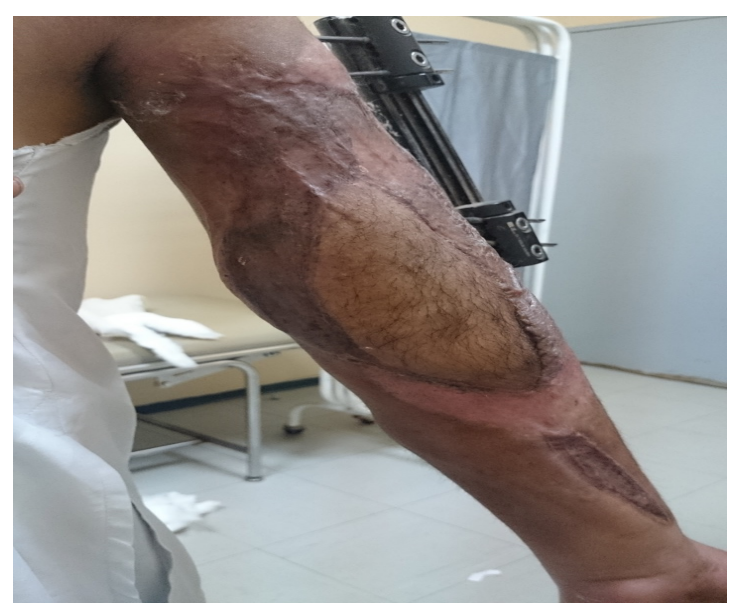

Figure 4. Case-2: Industrial accident compound fracture left humerus external fixator saphenous interposition graft post-op.

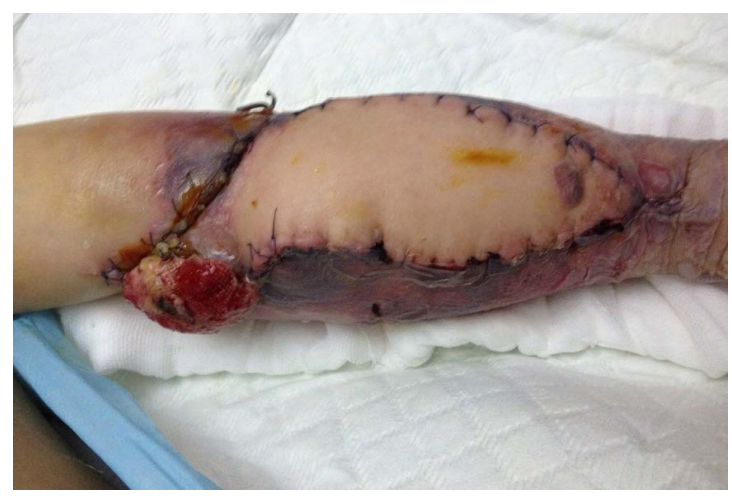

Figure 5. Case-3: immediate post-op antero-lateral thigh flap left upper limb. 


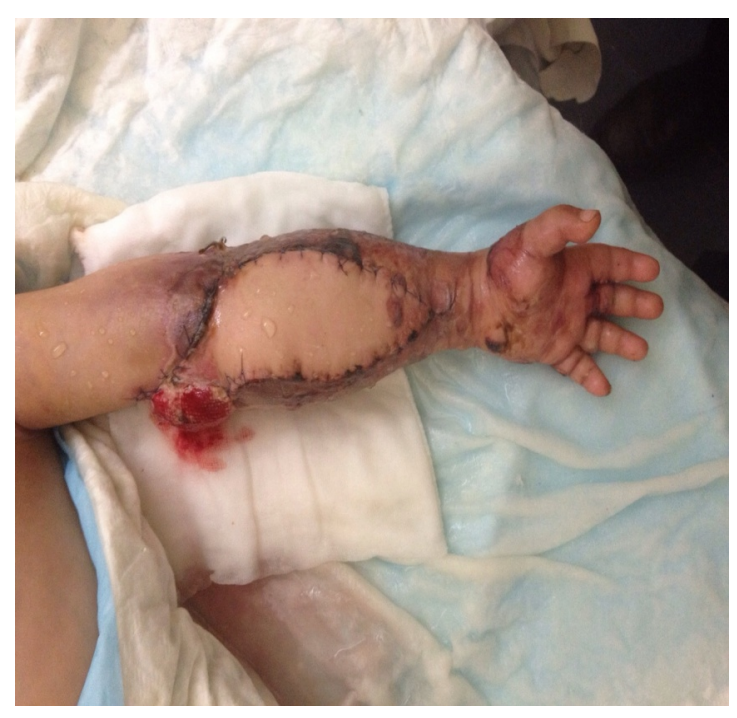

Figure 6. Case-3 Immediate post-op 3 days, minimal debridement was done and repeated wound acre.

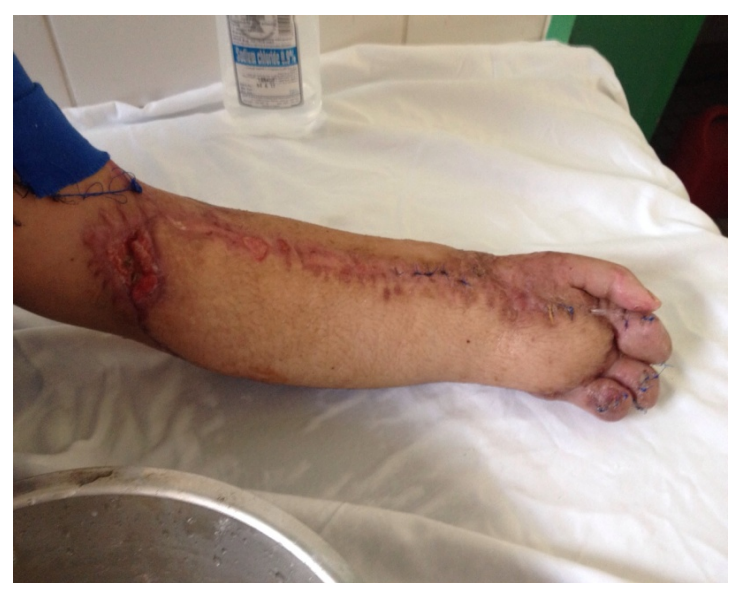

Figure 7. Case-3: RTA brachial artery repair with saphenous interposition, repair of median and ulnar nerve post-op 3 months.

Case 3: 19 years old male patient post road traffic accident with injury of the left upper limb, saphenous interpositon graft and median and ulnar nerve repair with immediate post operative photos showing minimal flap loss, minimal debridement and repeated wound care with healing 45 days post operative (Figures 5-7).

\section{Discussion}

Reconstructive surgery has been benefitted with the advancement in the field of microsurgical techniques. Free flaps can be designed with incorporating muscle, bone, fascia, skin, viscera, or omentum. Requirement for free flap is the dissection of vascular pedicle as well as presence of recipient vessel for anastomosis. The antero-lateral thigh flap is based on the descending branch of the lateral circumflex femoral artery which passes through the intermuscular septum between the rectus femoris and vastus lateralis. Proximally, it gives large branch to rectus femoris just after emerging from lateral circumflex femoral artery. This pedicle of the rectus femoris muscle should be preserved when possible [12]. Oblique branch of lateral circumflex femoral artery can be utilized as pedicle in antero-lateral thigh flap [13]. In study by Xu et al. of 872 patients of free anterolateral thigh flaps used in head and neck reconstruction showed success rate of 97.4\% [5]. Attainment of good aesthetic and functional outcome proper thickness of flap is to be done. Harvesting of free flap is a viable option. Sarkar et al. reported 
success of thin free antero-lateral thigh flap in covering defects of burn contracture of neck [14].

Antero-lateral can be sensate if lateral femoral cutaneous nerve is harvested in flap [15]. Since perforators run perpendicular after passing deep fascia, so thinning of adipose tissue can be done without compromising vascular supply in antero-lateral thigh flap. Location of perforators plays a major part in harvesting antero-lateral thigh flap. Localization of perforator can be done by color Doppler flowmetry which is very much reliable [16] [17]. Anatomical location for perforators is expected within $3 \mathrm{~cm}$ circle centered on midpoint of line connecting anterior superior iliac spine and lateral border of patella. Chimeric flap can be made which include separate skin islands on different perforators and/or muscle on individual muscle branches [18] [19]. Dissection beneath fascia makes easier isolation of perforator and spares suprafascial plexus. Very thin flap of 2 to $4 \mathrm{~mm}$ up to subdermal plexus has been successful in many studies [20]-[22]. Trauma in younger population may result in complex defects in upper extremities and with the absence of proper coverage in such patients the only solution that will be offered will be a major amputation. Using anterolateral thigh flaps may help in limb salvage [23]. Antero-lateral thigh flaps has advantage of large skin island, reliable long pedicle, easy dissection makes it an ideal flap.

\section{Conclusion}

The anterolateral thigh flap is one of the most versatile and useful perforator flaps for multidimensional reconstructions for head, neck, limb, trunk, and perineal region. It can be made ultrathin flap for resurfacing and filling dead spaces with superior functional and aesthetic outcomes. Complex defects are caused by traumatic injury to upper extremity and they require urgent coverage with flap. Due to scaricity of flap which can be used in upper limb like LD flap (latissimus dorsi flap), the use of antero-lateral thigh flap is a viable option.

\section{References}

[1] Song, Y.G., Chen, G.Z. and Song, Y.L. (1984) The Free Thigh Flap: A New Free Flap Concept Based on the SeptoCutaneous Artery. British Journal of Plastic Surgery, 37, 149-159. http://dx.doi.org/10.1016/0007-1226(84)90002-X

[2] Baek, S.M. (1983) Two New Cutaneous Free Flaps: The Medial and Lateral Thigh Flaps. Plastic \& Reconstructive Surgery, 71, 354-365. http://dx.doi.org/10.1097/00006534-198303000-00012

[3] Koshima, I., Fukuda, H., Yamamoto, H., Moriguchi, T., Soeda, S. and Ohta, S. (1993) Free Anterolateral Thigh Flaps for Reconstruction of Head and Neck Defects. Plastic \& Reconstructive Surgery, 92, 421-428; discussion 429-230. http://dx.doi.org/10.1097/00006534-199309000-00005

[4] Kimata, Y., Uchiyama, K., Ebihara, S., Yoshizumi, T., Asai, M., Saikawa, M., et al. (1997) Versatility of the Free Anterolateral Thigh Flap for Reconstruction of Head and Neck Defects. Archives of Otolaryngology-Head and Neck Surgery, 123, 1325-1331. http://dx.doi.org/10.1001/archotol.1997.01900120075012

[5] Shieh, S.J., Chiu, H.Y., Yu, J.C., Pan, S.C., Tsai, S.T. and Shen, C.L. (2000) Free Anterolateral Thigh Flap for Reconstruction of Head and Neck Defects Following Cancer Ablation. Plastic \& Reconstructive Surgery, 105, 2349-2357; discussion 2358-2360. http://dx.doi.org/10.1097/00006534-200006000-00006

[6] Koshima, I. (2000) Free Anterolateral Thigh Flap for Reconstruction of Head and Neck Defects Following Cancer Ablation. Plastic \& Reconstructive Surgery, 105, 2358-2357; discussion 2358-2360.

[7] Kuo, Y.R., Yeh, M.C., Shih, H.S., Chen, C.C., Lin, P.Y., Chiang, Y.C. and Jeng, S.F. (2009) Versatility of the Anterolateral Thigh Flap with Vascularized Fascia Lata for Reconstruction of Complex Soft-Tissue Defects: Clinical Experience and Functional Assessment of the Donor Site. Plastic \& Reconstructive Surgery, 124, 171-180. http://dx.doi.org/10.1097/PRS.0b013e3181a80594

[8] Luo, S., Raffoul, W., Luo, J., et al. (1999) Anterolateral Thigh Flap: A Review of 168 Cases. Microsurgery, 19, 232238. http://dx.doi.org/10.1002/(SICI)1098-2752(1999)19:5<232::AID-MICR5>3.0.CO;2-S

[9] Wei, F.C., Jain, V., Celik, N., Chen, H.C., Chuang, D.C. and Lin, C.H. (2002) Have We Found an Ideal Soft-Tissue Flap? An Experience with 672 Anterolateral Thigh Flaps. Plastic \& Reconstructive Surgery, 109, 2219-2226; discussion 2227-2230. http://dx.doi.org/10.1097/00006534-200206000-00007

[10] Lutz, B.S. and Wei, F.C. (2005) Microsurgical Workhorse Flaps in Head and Neck Reconstruction. Clinics in Plastic Surgery, 32, 421-430. http://dx.doi.org/10.1016/j.cps.2005.02.006

[11] Ali, R.S., Bluebond-Langner, R., Rodriguez, E.D. and Cheng, M.-H. (2009) The Versatility of the Anterolateral Thigh Flap. Plastic \& Reconstructive Surgery, 124, e395-e407.

[12] Mathes, S. and Nahai, F. (n.d.) Reconstructive Surgery: Principles, Anatomy and Technique. Vol. 2. QMP, St Louis, 1233-1246. 
[13] Wong, C.H., Wei, F.C., Fu, B., Chen, Y.A. and Lin, J.Y. (2009) Alternative Vascular Pedicle of the Anterolateral Thigh Flap: Theoblique Branch of the Lateral Circumflex Femoral Artery. Plastic \& Reconstructive Surgery, 123, 571-577. http://dx.doi.org/10.1097/PRS.0b013e318195658f

[14] Sarkar, A., Raghavendra, S., JeelaniNaiyer, M.G., et al. (2014) Free thin Anterolateral Thigh Flap for Post-Burn Neck Contractures-A Functional and Aesthetic Solution. Annals of Burns and Fire Disasters, 27, 209-214.

[15] Boca, R., Kuo, Y.R., Hsieh, C.H., Huang, E.Y. and Jeng, S.F. (2010) A Reliable Parameter for Primary Closure of the Free Anterolateral Thigh Flap Donor Site. Plastic \& Reconstructive Surgery, 126, 1558-1562. http://dx.doi.org/10.1097/PRS.0b013e3181ef8cb7

[16] Iida, H., Kishimoto, S., Umeda, T., et al. (2003) Preoperative Assessment of Anterolateral Thigh Flap Cutaneous Perforators by Colour Doppler Flowmetry. British Journal of Plastic Surgery, 56, 21-25. http://dx.doi.org/10.1016/S0007-1226(03)00018-3

[17] Tsukino, A., Kurachi, K., Inamiya, T., et al. (2004) Preoperative Color Doppler Assessment in Planning of Anterolateral Thigh Flaps. Plastic \& Reconstructive Surgery, 113, 241-246. http://dx.doi.org/10.1097/01.PRS.0000095949.41413.88

[18] Koshima, I., Yamamoto, H., Hosoda, M., et al. (1993) Free Combined Composite Flaps Using the Lateral Circumflex Femoral System for Repair of Massive Defects of the Head and Neck Regions: Anintroduction to the Chimeric Flap Principle. Plastic \& Reconstructive Surgery, 92, 411-420. http://dx.doi.org/10.1097/00006534-199309000-00004

[19] Tsai, F.C., Yang, J.Y., Mardini, S., et al. (2004) Free Split-Cutaneous Perforator Flaps Procured Using a ThreeDimensional Harvest Technique for the Reconstruction of Postburn Contracture Defects. Plastic \& Reconstructive Surgery, 113, 185-193. http://dx.doi.org/10.1097/01.PRS.0000096707.22461.8A

[20] Ross, G.L., Dunn, R., Kirkpatrick, G., et al. (2003) To Thin or Not to Thin: The Use of the Anterolateral Thigh Flap in the Reconstruction of Intraoral Defects. British Journal of Plastic Surgery, 56, 409-413.

http://dx.doi.org/10.1016/S0007-1226(03)00126-7

[21] Kimura, N., Satoh, K., Hasumi, T., et al. (2001) Clinical Application of the Free Thin Anterolateral Thigh Flap in 31 Consecutive Patients. Plastic \& Reconstructive Surgery, 108, 1197-1208. http://dx.doi.org/10.1097/00006534-200110000-00015

[22] Kimura, N. and Satoh, K. (1996) Consideration of a Thin Flap as an Entityand Clinical Applications of the Thin Anterolateral Thigh Flap. Plastic \& Reconstructive Surgery, 97, 985-992.

http://dx.doi.org/10.1097/00006534-199604001-00016

[23] Jordan, D.J., Malahias, M., Hindocha, S. and Juma, A. (2014) Flap Decisions and Options in Soft Tissue Coverage of the Lower Limb. The Open Orthopaedics Journal, 8, 423-432.

\section{Submit or recommend next manuscript to SCIRP and we will provide best service for you:}

Accepting pre-submission inquiries through Email, Facebook, Linkedin, Twitter, etc A wide selection of journals (inclusive of 9 subjects, more than 200 journals)

Providing a 24-hour high-quality service

User-friendly online submission system

Fair and swift peer-review system

Efficient typesetting and proofreading procedure

Display of the result of downloads and visits, as well as the number of cited articles

Maximum dissemination of your research work

Submit your manuscript at: http://papersubmission.scirp.org/ 